\title{
Association Between Multimorbidity and Depressive Symptom Among Community-Dwelling Elders in Eastern China
}

This article was published in the following Dove Press journal: Clinical Interventions in Aging

\author{
Liuqing You' \\ Zhebin Yu (1D' \\ Xiaocong Zhang' \\ Mengyin $\mathrm{Wu}^{\prime}$ \\ Shujuan Lin' \\ Yao Zhu' \\ Zenghao $\mathrm{Xu}^{\prime}$ \\ Jieming Lu' \\ Fang Wei ${ }^{\prime}$ \\ Mengling Tang' \\ Jianbing Wang' \\ Mingjuan Jin' \\ Kun Chen ${ }^{1,2}$ \\ 'Department of Epidemiology and \\ Biostatistics, Zhejiang University School \\ of Medicine, Zhejiang, Hangzhou, People's \\ Republic of China; ${ }^{2}$ Cancer Institute, \\ The Second Affiliated Hospital, Zhejiang \\ University School of Medicine, Hangzhou, \\ People's Republic of China
}

Purpose: This study aimed to investigate the prevalence of depressive symptoms and the association between multimorbidity and depressive symptoms among the elderly in eastern China. Patients and methods: A multicenter cross-sectional study was conducted in four cities (Jianggan, Yiwu and Anji in Zhejiang Province and Taixing in Jiangsu Province) in eastern China. We collected the information on 27 chronic conditions through the self-reported medical history and used the Geriatric Depression Scale (GDS) short form to evaluate depressive symptoms. Multivariate Logistic regression was used to evaluate the relationship between multimorbidity and depressive symptoms.

Results: Five thousand two hundred and ninety-six participants were included into the current study, among which 2687 (50.74\%) were female, with the mean \pm SD age $72.0 \pm$ 8.1 years old. The overall prevalence of depressive symptoms in eastern China was $23.5 \%$. And the percentage of multimorbidity in depressed participants was higher compared with non-depressed participants $(50.8 \%$ vs $38.8 \%, P<0.001)$. The univariate model and adjusted model suggested that participants with multiple chronic diseases were more likely to have a depressive symptom (adjusted $\mathrm{OR}=1.42$; 95\% CIs 1.19-1.70).

Conclusion: Depressive symptom was significantly associated with multimorbidity among the community-dwelling elderly population in eastern China.

Keywords: depressive symptom, multimorbidity, social health, elders

\section{Introduction}

Depression is one of the most common mental diseases found in the elderly population and is also one of the leading diseases contributing to global disease burden. ${ }^{1,2}$ It has been predicted that depression will become the second leading cause of disability by $2020 .^{3}$

Previous researches have documented the relationship between depression and specific chronic diseases including diabetes, asthma and coronary heart disease. ${ }^{4-8}$ However, only a few research have investigated the relationship between depressive symptoms and the presence of two or more chronic diseases, defined as multimorbidity. ${ }^{9}$ Multimorbidity is becoming more and more common in medical practice and its prevalence is rapidly increasing, ${ }^{10}$ largely due to the global aging population trend. ${ }^{11}$ Eckerblad et al found that the elderly with multimorbidity had a persistent high symptom burden (dry mouth, lack of energy, difficult sleep, etc.). ${ }^{12}$ Consequently, it is of great significance to explore the relationship between multimorbidity and depressive symptoms. 
Although there are already some researches on depression and multimorbidity, the types of chronic diseases included in their studies are relatively limited, which have an evidently negative impact on the judgment of the association between depressive symptom and multimorbidity. In the current study, we included 27 types of common chronic diseases. Our aim was to explore the association between depressive symptoms and multimorbidity in a more comprehensive view.

\section{Materials and Methods Study Design and Participants}

A multicenter cross-sectional study was conducted in four cities (Jianggan, Yiwu and Anji in Zhejiang Province and Taixing in Jiangsu Province) in eastern China. This study was approved by the Ethics committee at Zhejiang University school of medicine. Written informed consent was obtained from all participants before the face-to-face interview. People aged 60 years old and above and living in local communities for more than 5 years were included in the current study. Elderly people who were bed-ridden had serious physiological or psychological illness, and/or had hearing disorders were excluded. A total of 5619 participants finished the face-to-face interview and 323 participants with incomplete information in GDS-S (missing one or several items in GDS-S) were excluded.

\section{Data Collection}

We adopted a face-to-face interview technique to collect each participant's information through a general questionnaire. The interview was conducted at the local community health service center. And proxy-based interviews or complete the questionnaire by participants themselves were not allowed in the current study.

\section{Chronic Diseases and Multimorbidity}

Chronic disease was measured according to the participants' response to the question: "Do you suffer or were you told by a doctor that you suffer from the following problems in the past year?" (27 common chronic diseases were included: coronary heart disease, hypertension, orthostatic hypotension, diabetes, thyroid disease, osteoporosis, Parkinson, epilepsy, hemiplegia, cerebellar disease, peripheral neuropathy, stroke, asthma, COPD, chronic bronchitis, cervical spondylosis, lumbar spondylosis, arthritis, cancer, hepatitis, Cirrhosis, anemia, gastrointestinal band disease, glaucoma, cataract, prostate disease, foot disease.) The prevalence of self-reported chronic disease was coded as 0 (no) or 1 (yes) based on participants' response and the number of chronic diseases for each participant was counted. Multimorbidity was defined as having two or more chronic disease participants were classified into three groups (none, single, multiple).

\section{Depressive Symptom}

Geriatric Depression Scale-short form (GDS-S) was adopted to assess depressive symptoms. The GDS-S has 15 items which were coded as 0 (no) or 1 (yes) and its total score is 15 points. Lai, D. and his colleagues have presented evidence of the applicability of the GDS-S to elderly Chinese living in China and it appears to be an effective screening instrument for depression symptoms in the Chinese geriatric population. ${ }^{13}$ In this study, participants with a total GDS-S score of 8 or higher were considered to have depressive symptoms. ${ }^{14}$

\section{Socio-Demographic and Lifestyle}

Participants' demographic characteristics including area, city, age, gender, marital status, education level were collected. The area of the local community where participants lived was coded into urban or rural according to the national statistical zoning and urban-rural division code. (http://www. stats.gov.cn/tjsj/tjbz/tjyqhdmhcxhfdm/2018/index.html). In addition, the information about physical exercises and social health were also collected in our study. Physical exercises are defined as the frequency of physical exercise per week. Social health is an important dimension of health, alongside physical and mental health, which contains individual and social aspects, usually explained as "well-being", "adjustment" or other terms rather than "health"15,16 and is evaluated by the Social Health Scale for the Elderly (SHSE) which has been established and validated in Hangzhou elderly population with acceptable reliabilities and validities. ${ }^{17}$

\section{Statistical Analysis}

All descriptive statistics are presented as frequencies and percentages for categorical variables, and as means and standard deviations for continuous variables. Differences between depressed and non-depressed participants were tested using a $t$-test or non-parametric Wilcoxon test for continuous variables and $\chi^{2}$ tests or fisher-tests for categorical variables the association between multimorbidity and depressive symptom were compared using univariate and multivariable logistic regression analysis. The multivariable model was adjusted for sociodemographic and lifestyle characteristics including area, cities, age, gender, marital status, education level, physical exercise, and social health. 
Analyses were conducted for overall participants and were stratified by area, age, gender. Statistical analysis was performed using R software 3.5.2. Statistical significance was accepted for $\mathrm{p}$ values $<0.05$ (two-sided).

\section{Results}

\section{General Characteristics of Participants}

The characteristics of the study sample are presented in Table 1. Of 5296 participants, 23.5\% were classified as having a depressive symptom. Participants with depressive symptoms were more likely to live in an urban area, to be older, to be male, to have fewer physical activities and lower social health scores than those without depressive symptoms. The difference in married status $(P=0.491)$ and educational level $(P=0.148)$ between the people with depressive symptoms and without depressive symptoms was not significant. In addition, the distribution of participants with the number of chronic diseases (none, single, two or more) according to sex and age was shown in Figure 1. The prevalence of multimorbidity was higher than it in males (43.02\% vs $40.05 \%, P=0.046$ ), and the older population had

Table I Basic Characteristics of Selected Participants

\begin{tabular}{|c|c|c|c|c|}
\hline $\begin{array}{l}\text { Demographic (Total } \\
\text { 5296) }\end{array}$ & $\begin{array}{l}\text { All }(\mathrm{N}=5296) \text {, } \\
\text { n (\%) }\end{array}$ & $\begin{array}{l}\text { Nondepressed (GDS-sScore<8) } \\
(\mathrm{N}=405 \mathrm{I}), \mathrm{n}(\%)\end{array}$ & $\begin{array}{l}\text { Depressed (GDS-Score } \geq 8) \\
(\mathrm{N}=\mid \mathbf{2 4 5}), \mathrm{n}(\%)\end{array}$ & $P$-value \\
\hline $\begin{array}{l}\text { Area } \\
\text { Rural } \\
\text { Urban }\end{array}$ & $\begin{array}{l}3840(72.5) \\
1456(27.5)\end{array}$ & $\begin{array}{l}3052(75.3) \\
999(24.7)\end{array}$ & $\begin{array}{l}788(63.3) \\
457(36.7)\end{array}$ & $<0.001$ \\
\hline $\begin{array}{l}\text { Cities } \\
\text { Anji } \\
\text { Taixing } \\
\text { Jianggan } \\
\text { Yiwu } \\
\text { Age (years old) } \\
60-74 \\
75 \text { and above }\end{array}$ & $\begin{array}{l}888(16.8) \\
1456(27.5) \\
1507(28.5) \\
1445(27.2) \\
72.05 \pm 8.1 \\
331 \mid(62.5) \\
1985(37.5)\end{array}$ & $\begin{array}{l}683(16.9) \\
1242(30.7) \\
999(24.7) \\
1127(27.8) \\
71.8 \pm 8.0 \\
2580(63.7) \\
147 \mid(36.3)\end{array}$ & $\begin{array}{l}205(16.5) \\
265(21.3) \\
457(36.7) \\
318(25.5) \\
72.7 \pm 8.3 \\
731(58.7) \\
514(41.3)\end{array}$ & $\begin{array}{l}<0.001 \\
\\
<0.001 \\
0.002\end{array}$ \\
\hline $\begin{array}{c}\text { Gender } \\
\text { Male } \\
\text { Female }\end{array}$ & $\begin{array}{l}2609(49.3) \\
2687(50.7)\end{array}$ & $\begin{array}{l}2053(50.7) \\
1998(49.3)\end{array}$ & $\begin{array}{l}556(44.7) \\
689(55.3)\end{array}$ & $<0.001$ \\
\hline $\begin{array}{l}\text { Married Status } \\
\text { Married } \\
\text { Widowed } \\
\text { Others }\end{array}$ & $\begin{array}{l}3442(65.0) \\
849(16.0) \\
1005(19.0)\end{array}$ & $\begin{array}{l}2648(65.4) \\
637(15.7) \\
766(18.9)\end{array}$ & $\begin{array}{l}794(63.8) \\
212(17.0) \\
239(19.2)\end{array}$ & 0.491 \\
\hline $\begin{array}{l}\text { Educational Level } \\
\text { Low } \\
\text { Middle } \\
\text { High }\end{array}$ & $\begin{array}{l}3094(58.4) \\
1356(15.6) \\
846(16.0)\end{array}$ & $\begin{array}{l}2382(58.8) \\
1044(25.8) \\
625(15.4)\end{array}$ & $\begin{array}{l}712(57.2) \\
312(25.1) \\
221(17.8)\end{array}$ & 0.148 \\
\hline $\begin{array}{l}\text { Physical Exercise } \\
\text { (Times per Week) } \\
0 \\
1-2 \\
3-4 \\
5-7 \\
8 \text { or more }\end{array}$ & $\begin{array}{l}2265(42.8) \\
517(9.8) \\
425(8.0) \\
1719(32.4) \\
370(7.0)\end{array}$ & $\begin{array}{l}1655(40.9) \\
418(10.3) \\
326(8.0) \\
1395(34.4) \\
257(6.3)\end{array}$ & $\begin{array}{l}610(49.0) \\
99(8.0) \\
99(8.0) \\
324(26.0) \\
113(9.1)\end{array}$ & $<0.001$ \\
\hline $\begin{array}{l}\text { Social health score } \\
\text { Low } \\
\text { Middle } \\
\text { High }\end{array}$ & $\begin{array}{l}49.05 \pm 10.08 \\
953(18.0) \\
3552(67.1) \\
790(14.9)\end{array}$ & $\begin{array}{l}49.44 \pm 9.89 \\
673(16.6) \\
2760(68.1) \\
617(15.2)\end{array}$ & $\begin{array}{l}47.76 \pm 10.60 \\
280(22.5) \\
792(63.6) \\
173(13.9)\end{array}$ & $\begin{array}{l}<0.001 \\
<0.001\end{array}$ \\
\hline
\end{tabular}

Note: ${ }^{a} P$-value was measured using Chi-square tests for categorical variables and $T$-test for continuous variables. 

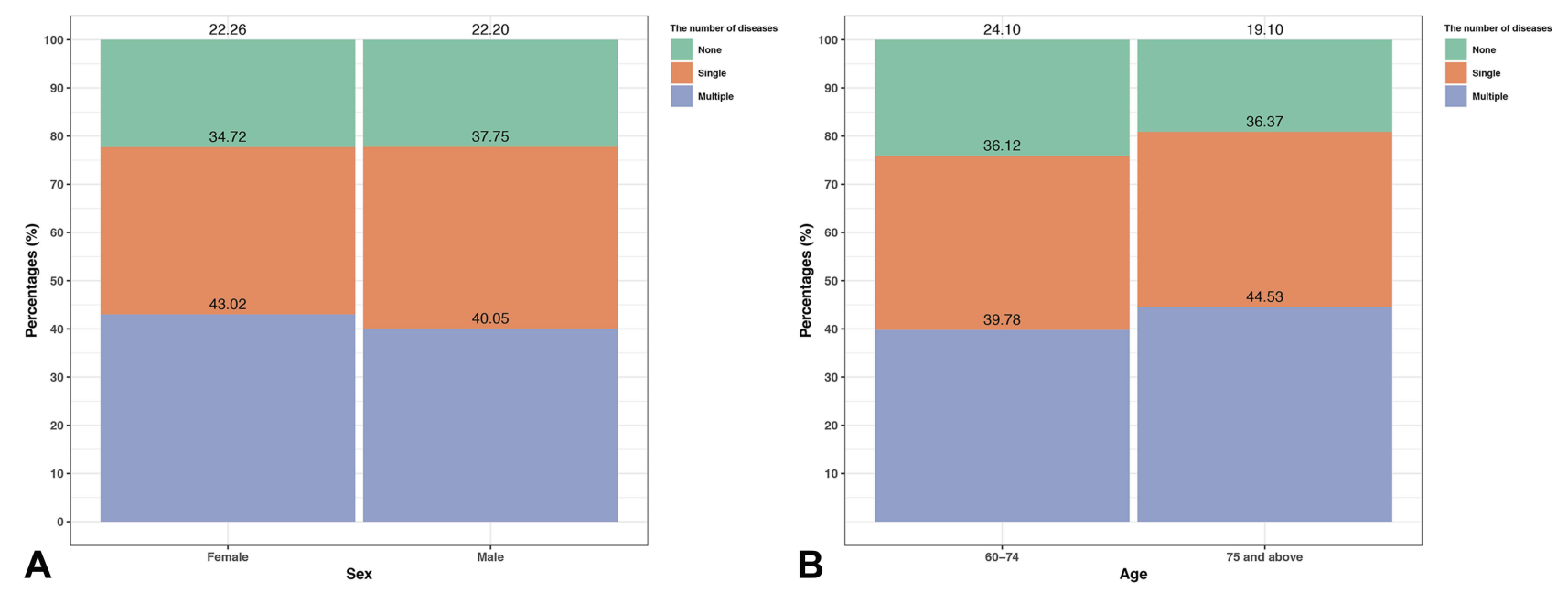

Figure I The distribution of the number of comorbidities according to sex (A) and age (B).

a higher prevalence (44.53\% in "75 and above" age group vs $39.78 \%$ in " $60-74$ " age group, $P<0.001$ ).

\section{Clinical Characteristics of Selected Participants}

We have supplemented clinic characteristics of selected participants and the adjusted ORs of the relationships between specific diseases and depressive symptoms in Supplementary Table 1. We found that coronary heart disease, stroke, COPD, chronic bronchitis, cervical spondylosis, hepatitis, glaucoma, cataract, and foot disease contributed significantly to an increased risk of depression at the single disease level.

\section{Multimorbidity Difference Between Depressed and Non-depressed People}

The percentage of multimorbidity in participants with depressive symptoms was higher compared with those without depressive symptoms $(50.7 \%$ vs $38.8 \%)$. Both the univariate model and adjusted model suggested that participants with multiple chronic diseases were more likely to have a depressive symptom (adjusted $\mathrm{OR}=1.42$; 95\% CIs 1.19-1.70). More details are listed in Table 2.

\section{Subgroups Analysis}

Subgroups analyses were conducted according to the area, age, and gender. The association between multimorbidity and depressive symptom was significant for participants living in rural area (adjusted $\mathrm{OR}=1.39 ; 95 \% \mathrm{CI} 1.14,1.71$ ), both for participants aged 60-74 (adjusted OR=1.33; 95\% CIs 1.06, 1.67) and participants aged 75 and above (adjusted $\mathrm{OR}=1.53$; $95 \%$ CIs 1.13, 2.07), and both for male (adjusted $\mathrm{OR}=1.58$; $95 \%$ CI $1.21,2.07$ ) and female (adjusted $\mathrm{OR}=1.29 ; 95 \% \mathrm{CI}$ $1.02,1.65)$. More details are shown in Figure 2.

\section{Discussion}

Based on a large group of elders in eastern China, we found a significant relationship between multimorbidity and depressive symptoms. People with multiple chronic diseases had $42 \%$ higher odds of having depressive symptoms as compared with those without a history of chronic disease after adjusting for the area, cities, age, gender, married status, educational level, physical exercise, and social health. Only a few studies reported the relationship between multimorbidity and depressive symptom and most of the studies have reported the relationship as a secondary focus and not classified the number

Table 2 Association Between Multimorbidity and Depression Symptom Among the Elderly in Eastern China

\begin{tabular}{|l|l|l|l|l|l|}
\hline $\begin{array}{l}\text { The Number } \\
\text { of Diseases }\end{array}$ & Nondepressed, n (\%) & Depressed, $\mathbf{n ~ ( \% ) ~}$ & Crude OR (95\% Cls) $^{\mathbf{a}}$ & Adjusted OR (95\% Cls) $^{\mathbf{b}}$ & $\begin{array}{l}\mathbf{P}_{\text {for }} \\
\text { Trend }\end{array}$ \\
\hline $\begin{array}{l}\text { Overall } \\
\text { None }\end{array}$ & $946(23.4)$ & $231(18.6)$ & $1($ Ref) & \\
Single & $1535(37.9)$ & $383(30.8)$ & $1.02(0.85,1.23)$ & I (Ref) \\
Multiple & $1570(38.8)$ & $631(50.7)$ & $1.65(1.39,1.96)$ & $1.00(0.83,1.21)$ \\
\hline
\end{tabular}

Notes: ${ }^{a}$ Univariate model. ${ }^{b}$ Multivariable model with adjustments on area, cities, age, gender, married status, educational level, physical exercise, and social health. 
Area

Rural

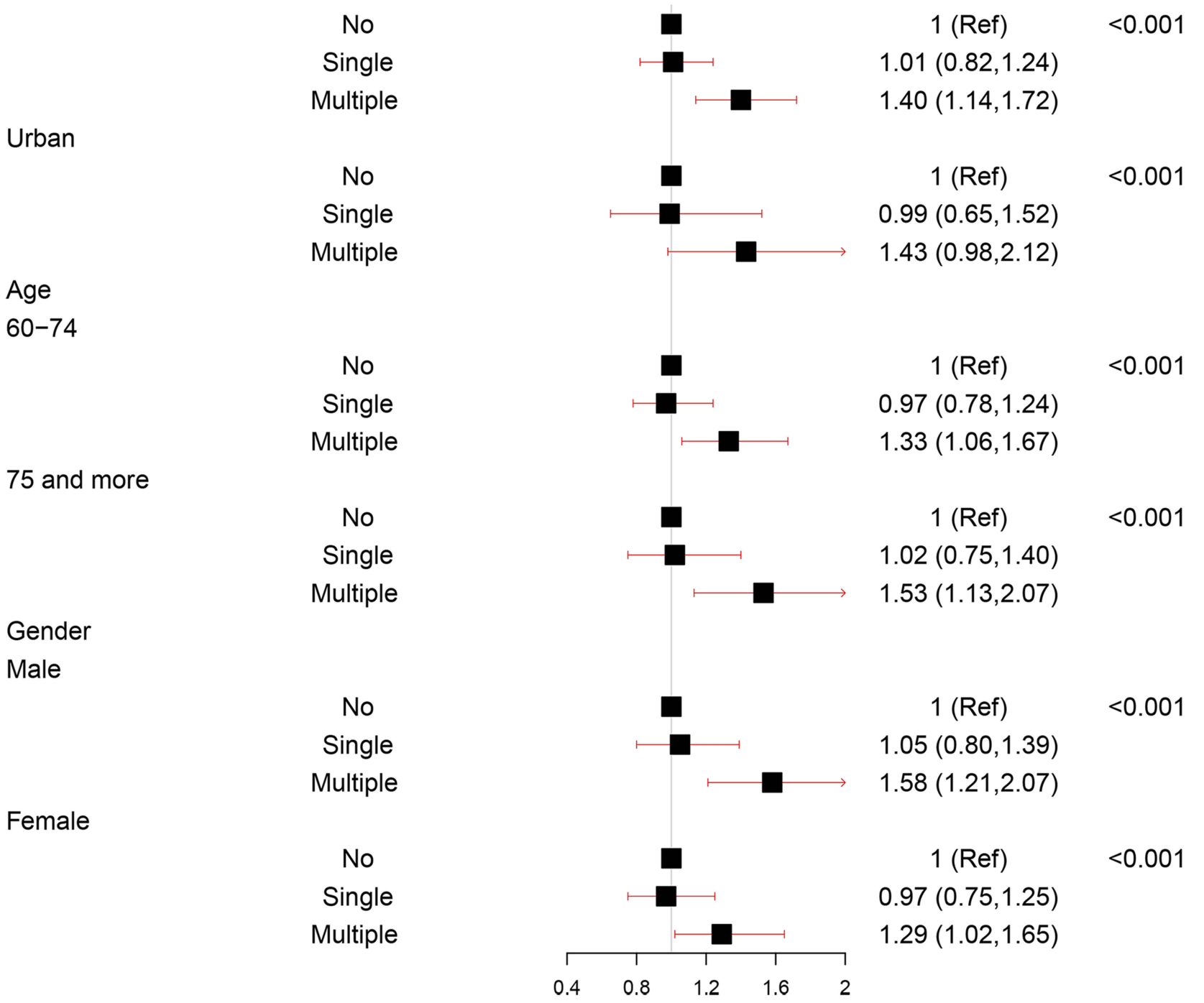

Figure $\mathbf{2}$ The association between multimorbidity and depressive symptoms in subgroups analysis.

of chronic diseases into the same groups. ${ }^{2}$ Yunming et al found that the elderly with three chronic diseases or above were more likely to have a depressive symptom (adjusted OR:2.03 $(1.21,3.42))$ which was higher than our data (adjusted OR:1.42 (1.19,1.70)). ${ }^{18}$ Tsai and colleagues found that the number of co-morbidities was associated with depression symptoms (adjusted OR:1.34 (1.28,1.40)). ${ }^{19}$ Although the comparison with other studies is limited due to the grouping, study setting, and population, they all confirmed that multimorbidity was an important risk factor for depressive symptoms among the elderly.

A previous review held that diseases of multimorbidity may interact with each other, curtailing compensatory mechanisms and resulting in physical and cognitive decline. And physical and cognitive impairment might, in turn, impact the severity and burden of multimorbidity, contributing to the establishment of a vicious circle. ${ }^{20}$ What is more, a previous study has suggested that some specific chronic diseases would cause or contribute to depression by directly biological mechanisms. ${ }^{21}$ For instance, diabetes, stroke, and thyroid disorders were likely to cause pathophysiological aberrations in the brain, endocrine or immune function to affect the depression. ${ }^{22}$ Hence, multimorbidity might contribute to a higher risk of depressive symptoms through a vicious circle, and findings of positive relationship in the current study are reasonable. 
It should be noted that our results also had implications for clinical practice. Although the prevalence of multimorbidity in our study is $41.56 \%$ which is lower than $56.66 \%$ obtained from $\mathrm{Gu}^{23}$ it also means that the number of elders with multimorbidity, in eastern China, is still very large. At the same time, previous studies showed that people with both chronic physical status and depressive symptoms have a poorer quality of life and higher death risk than those with chronic physical conditions but not depressive symptom. ${ }^{24,25}$ Hence, given the fact that multimorbidity is strongly associated with depression symptoms among the elderly population, it suggested that more attention should be paid to those older adults with two or more chronic diseases when intervention for preventing depressive symptoms as early as possible from the intervention perspectives.

In the subgroup analysis, some differences were found. The relationship between multimorbidity and depression symptoms in an urban area was not significant (adjusted OR:1.43 $(0.98,2.12))$ while this association was significant in a rural area (adjusted OR:1.40 $(1.14,1.72)$ ). From this, we could infer that the elders living in a rural area were more sensitive to chronic diseases and thereby likely to have depressive symptoms which were consistent with the study of Keats, M. ${ }^{26}$ While the reason for these phenomena is unclear, the findings appear to support the need to further explore "area-sensitive" health-care interventions. ${ }^{27}$

In addition, we found that the prevalence of depressive symptoms in our study was $23.5 \%$ which was lower than the reported data, $60.6 \%$ obtained from Kathmandu, Nepal with a small sample size (303 participants). ${ }^{28}$ The previous study conducted in Taiwan by Chiu et al showed that the prevalence of depressive symptoms was $20.1 \%{ }^{29}$ Our results were consistent with this prevalence data. The heterogeneity of the depression prevalence between different studies may be due to the different populations and the sample size.

Our study also confirmed several health-related factors associated with depressive symptoms. Firstly, we found significantly lower odds of having depressive symptoms among rural elderly compared with urban elderly in our study. ${ }^{30,31}$ Secondly, similar to the study of Kuehner, C. and the study of Forlani. $\mathrm{C},{ }^{32,33}$ the female had a significantly higher prevalence of depression symptoms compared to the male. Thirdly, the elderly with depressive symptom has lower social health which is consistent with previous studies. ${ }^{34-36}$

The strengths of our study included the large sample size, the use of stratified sampling method by sex and age and multivariate regression analyses adjusted for the area, age, gender, marital status, educational level, physical exercise, and social health. However, there were several limitations that should be noted when interpreting our results. Firstly, only association but not causality between multimorbidity and depressive symptom can be inferred from our results, due to the cross-sectional study design, in which the data including exposure and outcome collected concurrently. Further longitudinal researches are needed to infer their causal temporality. Secondly, neither random sampling survey nor census was performed in our study and there were some people refusing to participate in our study. Thus, the representativeness was relatively limited. Thirdly, GDS-15 was used in our study, which might overestimate the prevalence of depressive symptoms compared to structured interviews. The reason why we choose GDS-15 as the measurement of depression symptom is the low time costs of this scale which can overcome distraction and fatigue during the interview of elders. The GDS-15 also had acceptable reliability and validity and had been widely used in the Chinese elderly. Fourthly, volunteer bias should be taken into consideration although no cash only gifts worth $10 \mathrm{RMB}$ were given to each participant who finished the interview. Finally, the majority assessed the presence or absence of multimorbidity by self-reported measures which might lead to confoundings.

\section{Conclusion}

In this study, we observed significantly higher odds of having depressive symptoms among the multimorbid elderly in eastern China. The association between multimorbidity and depressive symptoms was consistent after adjusting for confounding factors and across several subgroups. The multimorbidity may serve as an efficient screener to identify those with the depressive symptom, but systematic assessment to guide intervention merits further longitudinal research.

\section{Acknowledgments}

This study was funded by the Ministry of Science and Technology of the People's Republic of China (No.2015F Y111600). The authors would like to thank the nurses, clinicians and management staff in Primary Health Service Center of Kaixuan, Jianggan District, Hangzhou and medical students in the School of Medicine, Zhejiang University for their participation and support for this research.

\section{Ethics}

All procedures followed were in accordance with the ethical standards of the responsible committee on human experimentation (institutional and national) and with the 
Helsinki Declaration of 1975, as revised in 2008 (5) Written informed consent was obtained from all participants for being included in the study.

\section{Disclosure}

The authors report no conflicts of interest in this work.

\section{References}

1. Sozeri-Varma G. Depression in the elderly: clinical features and risk factors. Aging Dis. 2012;3(6):465-471.

2. Read JR, Sharpe L, Modini M, Dear BF. Multimorbidity and depression: a systematic review and meta-analysis. J Affect Disord. 2017;221:36-46. doi:10.1016/j.jad.2017.06.009

3. Murray CJ, Lopez AD. Alternative projections of mortality and disability by cause 1990-2020: Global Burden of Disease Study. Lancet. 1997;349(9064):1498-1504. doi:10.1016/S0140-6736(96)07492-2

4. Dhar AK, Barton DA. Depression and the link with cardiovascular disease. Front Psychiatry. 2016;7:33. doi:10.3389/fpsyt.2016.00033

5. Park M, Reynolds CF 3rd. Depression among older adults with diabetes mellitus. Clin Geriatr Med. 2015;31(1):117-137. doi:10. 1016/j.cger.2014.08.022

6. Choi S, Kim SH, Lee JS. Association between depression and asthma in Korean adults. Allergy Asthma Proc. 2017;38(3):37-46. doi:10.2500/aap.2017.38.4051

7. Yu M, Zhang X, Lu F, Fang L. Depression and risk for diabetes: a meta-analysis. Can j Diabetes. 2015;39(4):266-272. doi:10.1016/j. jcjd.2014.11.006

8. Rudisch B, Nemeroff CB. Epidemiology of comorbid coronary artery disease and depression. Biol Psychiatry. 2003;54(3):227-240. doi:10.1016/S0006-3223(03)00587-0

9. van den Akker M, Buntinx F, Roos S, Knottnerus JA. Problems in determining occurrence rates of multimorbidity. $J$ Clin Epidemiol. 2001;54(7):675-679. doi:10.1016/S0895-4356(00)00358-9

10. van Oostrom SH, Gijsen R, Stirbu I, et al. Time trends in prevalence of chronic diseases and multimorbidity not only due to aging: data from general practices and health surveys. PLoS One. 2016;11(8): e0160264. doi:10.1371/journal.pone.0160264

11. Lutz W, Sanderson W, Scherbov S. The coming acceleration of global population ageing. Nature. 2008;451(7179):716-719. doi:10.1038/nature06516

12. Eckerblad J, Theander K, Ekdahl AW, Jaarsma T. Symptom trajectory and symptom burden in older people with multimorbidity, secondary outcome from the RCT AGe-FIT study. $J$ Adv Nurs. 2016;72 (11):2773-2783. doi:10.1111/jan.2016.72.issue-11

13. Lai D, Tong H, Zeng Q, Xu W. The factor structure of a Chinese Geriatric Depression Scale-SF: use with alone elderly Chinese in Shanghai, China. Int J Geriatr Psychiatry. 2010;25(5):503-510. doi:10.1002/gps.v25:5

14. Tang WK, Wong E, Chiu HF, Lum CM, Ungvari GS. The Geriatric Depression Scale should be shortened: results of Rasch analysis. Int J Geriatr Psychiatry. 2005;20(8):783-789. doi:10.1002/gps.1360

15. International Health Conference. Constitution of the World Health Organization. 1946. Bull World Health Organ. 2002;80(12):983-984.

16. Russell RD. Social health: an attempt to clarify this dimension of well being. Int J Health Educ. 1973;16(2):74-84.

17. Bao C, Yu Z, Yin X, et al. The development of the social health scale for the elderly. Health Qual Life Outcomes. 2018;16(1):67. doi:10.1186/s12955-018-0899-6

18. Yunming L, Changsheng $\mathrm{C}$, Haibo $\mathrm{T}$, et al. Prevalence and risk factors for depression in older people in Xi' an China: a community-based study. Int J Geriatr Psychiatry. 2012;27(1):31-39. doi:10.1002/gps.2685
19. Tsai HJ. Nutrition risk, functional dependence, and co-morbidities affect depressive symptoms in Taiwanese aged 53 years and over: a population-based longitudinal study. J Psychosom Res. 2013;75 (2):173-177. doi:10.1016/j.jpsychores.2013.04.009

20. Calderón-Larrañaga A, Vetrano DL, Ferrucci L, et al. Multimorbidity and functional impairment-bidirectional interplay, synergistic effects and common pathways. J Intern Med. 2019;285(3):255-271. doi:10.1111/joim.2019.285.issue-3

21. Evans DL, Charney DS, Lewis L, et al. Mood disorders in the medically ill: scientific review and recommendations. Biol Psychiatry. 2005;58(3):175-189. doi:10.1016/j.biopsych.2005.05.001

22. Penninx BW, Beekman AT, Ormel J, et al. Psychological status among elderly people with chronic diseases: does type of disease play a part? J Psychosom Res. 1996;40(5):521-534. doi:10.1016/ 0022-3999(95)00620-6

23. Gu J, Chao J, Chen W, et al. Multimorbidity and health-related quality of life among the community-dwelling elderly: a longitudinal study. Arch Gerontol Geriatr. 2018;74:133-140. doi:10.1016/j.archger.2017.10.019

24. Moussavi S, Chatterji S, Verdes E, Tandon A, Patel V, Ustun B. Depression, chronic diseases, and decrements in health: results from the World Health Surveys. Lancet. 2007;370(9590):851-858. doi:10.1016/S0140-6736(07)61415-9

25. Chang CK, Hayes RD, Broadbent M, et al. All-cause mortality among people with serious mental illness (SMI), substance use disorders, and depressive disorders in southeast London: a cohort study. BMC Psychiatry. 2010;10:77. doi:10.1186/1471-244X-10-77

26. Keats MR, Cui Y, DeClercq V, et al. Multimorbidity in Atlantic Canada and association with low levels of physical activity. Prev Med. 2017;105:326-331. doi:10.1016/j.ypmed.2017.10.013

27. Regitz-Zagrosek V. Sex and gender differences in health. Science \& Society Series on Sex and Science. EMBO Rep. 2012;13(7):596-603. doi:10.1038/embor.2012.87

28. Simkhada R, Wasti SP, Gc VS, Lee ACK. Prevalence of depressive symptoms and its associated factors in older adults: a cross-sectional study in Kathmandu, Nepal. Aging Ment Health. 2018;22 (6):802-807. doi:10.1080/13607863.2017.1310803

29. Chiu HC, Chen CM, Huang CJ, Mau LW. Depressive symptoms, chronic medical conditions and functional status: a comparison of urban and rural elders in Taiwan. Int J Geriatr Psychiatry. 2005;20 (7):635-644. doi:10.1002/gps. 1292

30. Romans S, Cohen M, Forte T. Rates of depression and anxiety in urban and rural Canada. Soc Psychiatry Psychiatr Epidemiol. 2011;46(7):567-575. doi:10.1007/s00127-010-0222-2

31. Ghesquiere AR, Pepin R, Kinsey J, Bartels SJ, Bruce ML. Factors associated with depression detection in a New Hampshire mental health outreach program. Aging Ment Health. 2017;22:1-6.

32. Kuehner C. Why is depression more common among women than among men? Lancet Psychiatry. 2017;4(2):146-158. doi:10.1016/ S2215-0366(16)30263-2

33. Forlani C, Morri M, Ferrari B, et al. Prevalence and gender differences in late-life depression: a population-based study. Am $j$ Geriat Psychiatry. 2014;22(4):370-380. doi:10.1016/j.jagp.2012.08.015

34. Zeng W, North N, Kent B. Family and social aspects associated with depression among older persons in a Chinese context. Int $J$ Older People Nurs. 2013;8(4):299-308. doi:10.1111/opn.2013.8.issue-4

35. Yaka E, Keskinoglu P, Ucku R, Yener GG, Tunca Z. Prevalence and risk factors of depression among community dwelling elderly. Arch Gerontol Geriatr. 2014;59(1):150-154. doi:10.1016/j.archger.2014. 03.014

36. Wang S, Blazer DG. Depression and cognition in the elderly. Annu Rev Clin Psychol. 2015;11:331-360. doi:10.1146/annurev-clinpsy $-032814-112828$ 


\section{Publish your work in this journal}

Clinical Interventions in Aging is an international, peer-reviewed journal focusing on evidence-based reports on the value or lack thereof of treatments intended to prevent or delay the onset of maladaptive correlates of aging in human beings. This journal is indexed on PubMed Central, MedLine, CAS, Scopus and the Elsevier
Bibliographic databases. The manuscript management system is completely online and includes a very quick and fair peer-review system, which is all easy to use. Visit http://www.dovepress.com/ testimonials.php to read real quotes from published authors. 